\title{
Challenges of Airway Management in Emergency Situations: A Literature Review
}

\author{
Marco Felipe Bouzada Marcos ${ }^{1}$, Fernando Peribanez ${ }^{1}$, Larissa Alexsandra da Silva Neto Trajano ${ }^{1}$, Marco \\ Aurélio dos Santos Silva ${ }^{1}$, Carlos Eduardo Cardoso', Eduardo Tavares Lima Trajano ${ }^{1}$, Victor Hugo \\ Bastos $^{2}$, Silmar Teixeira ${ }^{2}$, Acary Bulle Oliveira ${ }^{3}$ and Marco Orsini*1,2
}

${ }^{1}$ Mestrado Profissional em Ciências Aplicadas em Saúde / Universidade de Vassouras-RJ, Brazil

${ }^{2}$ Brain Mapping and Plasticity Laboratory, Federal University of Piauí (UFPI), Brazil

${ }^{3}$ Universidade Federal de São Paulo - Escola Paulista de Medicina - UNIFESP - SP , Brazil

Received: June 16, 2018; Published: June 22, 2018

*Corresponding author: Marco Orsini, Mestrado Profissional em Ciências Aplicadas em Saúde / Universidade de Vassouras-RJ, Brain Mapping and Plasticity Laboratory, Federal University of Piauí (UFPI), Parnaíba, Brazil

\section{Abstract}

In emergency situations the approach of the airways is crucial for the reduction of the hypoxemia and consequently of the neurological damages. In prehospital care, the advanced management of the airways is pointed out as one of the five research priorities in prehospital critical care. The management of the airways is the first intervention in emergency situations as one of the recommendations of Advanced Trauma Life Support. Endotracheal intubation is a procedure of choice for doctors. However, the use of the pocket-valve-mask is effectively evidenced by a new two-hand sealing technique. The objective of this study is to perform a review on the management of the airways in emergency situations.

Keywords: Emergency; Airway Management; Endotracheal Intubation.

\section{Introduction}

The management of the airways in emergency situations is considered one of the main life-saving acts [1]. According to Advanced Trauma Life Support recommendations for the management of patients with life-threatening injuries, airway protection is the first intervention [2]. Endotracheal intubation is the technique of choice because it is a fast, more frequently successful procedure and allows the use of a larger tube [1,2]. They are indications for endotracheal intubation and emergency: maintenance of airway permeability, respiratory failure unrelated to upper airway obstruction, decreased risk of aspiration of gastric contents [2]. Evidence corroborated the findings that the efficacy of bag-valve-mask use in emergencies, most emergency intubations occur in situations of cardiorespiratory arrest, the difference in the development of pneumonia due to invasive airway management in a pre-operative environment -hospital and hospital are not significant and the combination of ketamine and propofol (known as cetofol) is an alternative for etomidate in sedation for maintaining hemodynamic stability [2-11]. The objective of this study is to perform a review on the management of the airways in emergency situations.

\section{Discussion}

\section{Air Handling in Emergency Situations}

In emergency situations the approach of the airways is crucial for the reduction of the hypoxemia and consequently of the neuro logical damages. In prehospital care, the advanced management of the airways is pointed out as one of the five research priorities in prehospital critical care [3]. Bag-valve-mask ventilation is a technique used in emergency situations [4]. The upgrades of Advanced Cardiovascular Life Support point to a high efficacy of the use of pocket-valve-mask in cardiorespiratory arrest when compared to endotracheal intubation [5]. The studies corroborate the lack of high-quality evidence that favors the use of endotracheal intubation compared to bag-valve-mask ventilation or an advanced airway device in relation to overall survival or favorable neurological outcome [5]. Many challenges are heightened in the emergency scenario and with this, physicians must be skilled with the management of the airways. Advances in airway management technology have helped improve many aspects of emergency management; however, besides the specialization, it is necessary to use the right equipment and the adequate understanding of the new technologies [6].

\section{Endotracheal Intubation}

Emergency endotracheal intubation is always necessary for airway maintenance, since it is not possible to predict emergency and emergency complications. The procedure can be difficult in emergency situations due to the lack of detailed history and detailed clinical examination [7]. In cases of maxillofacial trauma and airway 
trauma, airway management requires assessment of the nature of the trauma. There are six specific situations of maxillofacial trauma that adversely affect the airway [2]:

a) Posteroinferior displacement of a fractured maxilla parallel to the inclined plane of the skull base may block the nasopharyngeal airway.

b) A bilateral fracture of the anterior mandible may cause the fractured symphysis and tongue to later slide and block the oropharynx in the patient in the supine position.

c) fractured or exfoliated teeth, bone fragments, vomiting, blood and secretions, as well as foreign bodies, such as prostheses, fragments and shrapnel, can block the airways anywhere along the oropharynx and larynx.

d) hemorrhage from distinct vessels in open wounds or severe nasal bleeding due to complex blood supply to the nose may also contribute to airway obstruction.

e) Soft tissue swelling and edema resulting from trauma to the head and neck may cause delayed airway involvement.

f) trauma to the larynx and trachea can cause swelling and displacement of structures such as the epiglottis, arytenoid cartilages and vocal cords, thus increasing the risk of obstruction of the cervical airways.

\section{Clinical Evidence in the Airway Approach}

Evidence shows that most emergency intubations occur in situations of cardiorespiratory arrest [7]. Bag-valve-mask ventilation is an essential element of emergency airway management. It was evidenced that in this technique the use of both hands on the mask seal resulted in larger tidal volumes compared to the one hand technique [4,7]. According to Advanced Trauma Life Support recommendations for the management of patients who have suffered life-threatening injuries, maintenance of the airway with cervical spine immobilization is the first priority and the first action in the early management of the airways and endotracheal intubation a standard gold procedure [2]. Pre-oxygenation is effective by prolonging the time to the hypoxemic state $[2,8]$. Regarding complications related to invasive airway maintenance procedures, it was shown that the chances of developing pneumonia between prehospital and hospital exposure were not statistically significant [9]. Critically ill patients with acute respiratory, neurological or cardiovascular insufficiency who require invasive mechanical ventilation are at high risk of difficult intubation and present with organic dysfunctions associated with intubation and anesthesia complications such as hypotension and hypoxemia.

In these cases, the rate of complications increases with the number of intubation attempts and videolaryngoscopy is a technique that improves endotracheal intubation [10]. Several preventive measures are evidenced to minimize the frequency and severity of intubation-related complications, namely: proven and safe anesthetic agents for the rapid sequence of intubation; the use of a fast-acting neuromuscular blocker such as succinylcholine or rocuronium to facilitate the procedure and limit the risk of aspiration of gastric contents; pre-oxygenation for at least $3 \mathrm{~min}$ if necessary using non-invasive ventilation and fluid resuscitation and vasopressor support should be initiated early to ensure hemodynamic stability [10]. Recent evidence has raised concerns about the increased incidence of adrenal insufficiency and mortality associated with etomidate use. In recent years, studies have shown that the combination of ketamine and propofol (known as cetofol) is an alternative that can provide adequate sedation while maintaining hemodynamic stability [11].

\section{Conclusion}

We conclude that endotracheal intubation is the procedure of choice for physicians, however, the pocket-valve-mask when used in the two-hand technique in mask sealing results in larger tidal volumes compared to the one hand technique, which points to a high efficiency in emergencies. In this sense, studies that evaluate the use of emergency interventions in the maintenance of the airways, with consequences for improvements in survival, are important for clinical updates.

\section{References}

1. Falcão LFR, Costa LHD (2010) Capítulo 03 - Manejo das Vias Aéreas. IN: Falcão LFR Falcão, LFR; Costa, LHD; Amaral JLG (Eds.) Emergências fundamentos e práticas. (1ª Edição), Martinari, São Paulo, Brasil 1139: 21-31.

2. Barak M, Bahouth H, Leiser Y, El-Naaj IA (2015) Airway Management of the Patient with Maxillofacial Trauma: Review of the Literature and Suggested Clinical Approach. BioMed Research International 9(1): 1-9.

3. Tapgard M, Hansen TM, Rognas L (2015) Anaesthetist-provided prehospital advanced airway management in children: a descriptive study. Scandinavian Journal of Trauma, Resuscitation and Emergency Medicine $7(1): 1-7$.

4. Otten D, Liao MM, Wolken R, Douglas IS, Mishra R, et al. (2014) Comparison of Bag-Valve-Mask Hand-Sealing Techniques in a Simulated Model. Ann Emerg Med 63(1): 6-12.

5. Link MS, Berkow LC, Kudenchuk PJ, Halperin HR, Hess EP, et al. (2015) Part 7: Adult Advanced Cardiovascular Life Support. 2015 American Heart Association Guidelines Update for Cardiopulmonary Resuscitation and Emergency Cardiovascular Care 23(1): S444-S464.

6. Gazynski T, Toker K, Carassiti M, Chalkias A, Carlson JN (2015) Advances in Airway Management and Ventilation Strategies in Emergency Medicine. BioMed Research International 2(1): 1-2.

7. Mechlin MW, Hurford W E (2014) Emergency Tracheal Intubation: Techniques and Outcomes. Respiratory Care 59(6): 881-894.

8. Silva LOJ, Cabrera D, Barrinuevo P, Johnson RL, Erwin P, et al. (2017) Effectiveness of Apneic Oxygenation During Intubation: A Systematic Review and Meta-Analysis. Annals of Emergency Medicine 70(4): 483494.

9. Andrusiek DL, Szydlo D, May S, Brasel KJ, Minei J, et al. (2015) A comparison of invasive airway management and rates of pneumonia in prehospital and hospital. Prehosp Emerg Care 19(4): 475-481.

10. Bailly A, Lascarrou JB, Le Thuaut A, Boisrame-Helms J, Kamel T, et al. (2015) McGRATH MAC videolaryngoscope versus Macintosh laryngoscope for orotracheal intubation in intensive care patients: the randomised multicentre MACMAN trial study protocol. BMJ Open 5(12): e009855.

11. Scmichney NJ, Hoskote SS, Moraes AG, Africano CJR, Carrera PM, et al. (2015) Ketamine/propofol admixture (ketofol) at induction in the critically ill against etomidate (KEEP PACE trial): study protocol for a randomized controlled Trial. BioMed Central 16: 177. 
(C) (i) This work is licensed under Creative

Submission Link: https://biomedres.us/submit-manuscript.php

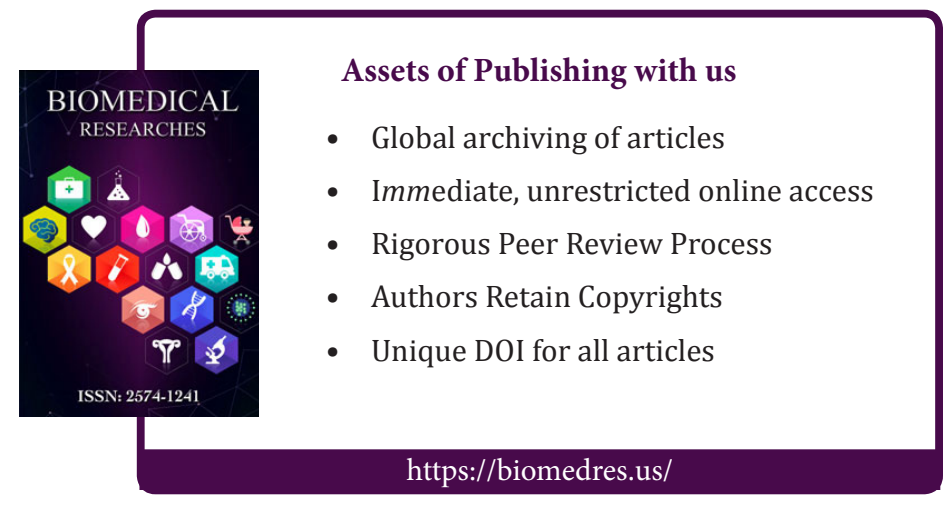

